\title{
NOTAS PARA UMA REFLEXÃO SOBRE CONSCIÊNCIA E INCONSCIENTE NA FENOMENOLOGIA ${ }^{1}$
}

\author{
Notes for a Reflection About Consciousness and Unconscious in Phenomenology \\ Notas para una Reflexión Cerca de la Conciencia y Inconsciente en la Fenomenología
}

ADRIANO Holanda

\begin{abstract}
Resumo: $\mathrm{O}$ artigo se propõe a discutir os conceitos de inconsciente e de consciência, a partir de um referencial fenomenológico. Partindo da metáfora de uma análise semântica da palavra "inconsciente”, busca desenvolver reflexões em torno de seu significado, fazendo uma contraposição com "consciência" e "consciente". Neste sentido, perpassa ainda as idéias de estrutura e processo, bem como ato e conteúdo, na direção da distinção entre substantivo e adjetivo. Como analogia, toma algumas idéias de Theodor Lipps a respeito do inconsciente, como entrada à temática da consciência na fenomenologia a partir da psicopatologia e da crítica de Merleau-Ponty à interioridade na psicologia, para afirmar, por fim, a idéia de uma consciência como posição do sujeito no mundo, e afirmar a fenomenologia como uma fenomenologia da consciência no mundo.
\end{abstract}

Palavras-chave: Fenomenologia; Consciência; Inconsciente; Mundo.

Abstract: The article proposes to discuss the concepts of the unconscious and conscience, from a phenomenological reference. Starting from the metaphor of a semantic analysis of the word "unconscious", seek to develop reflections around its significance, making a contraposition with "awareness" and "conscious". In this sense, still permeates the ideas of structure and process, as well as act and content, in the direction of the distinction between substantive and adjective. As analogy, take some ideas of Theodor Lipps in respect of the unconscious, as an entry to the subject of conscience in phenomenology using psychopathology and the criticism of Merleau-Ponty about the idea of interiority in psychology, to defend, finally, the idea of a conscience as position of the subject in the world, and affirm the phenomenology as a phenomenology of conscience in the world.

Keywords: Phenomenology; Awareness; Unconscious; World.

Resumen: El artículo propone una discusión cerca de los conceptos del inconsciente y de conciencia, de un referencial fenomenológico. A partir de la metáfora de un análisis semántica de la palabra "inconsciente”, trata de desarrollar reflexiones alrededor de su importancia, haciendo una contraposición mientras "conciencia" y "consciente". En este sentido, pasa por las ideas de estructura y proceso, así como acto y contenido, en la dirección de la distinción entre sustantivo y adjetivo. Como analogía, tomando algunas ideas de Theodor Lipps respecto del inconsciente, entra en el tema de la conciencia en fenomenología a partir de la psicopatología y de las críticas de Merleau-Ponty ante la cuestión de la interioridad en psicología, para defender, finalmente, la idea de una conciencia como posición del sujeto en el mundo, y afirmar la fenomenología como una fenomenología de conciencia en el mundo.

Palabras-clave: Fenomenología; Conciencia; Inconsciente; Mundo.

"Na maioria das vezes, as idéias inconscientes do paciente são as teorias conscientes de seu terapeuta" (Erwin Straus)

\section{Introdução}

A questão da consciência está no cerne do pensamento fenomenológico, mesmo quando este foi apropriado pelos diversos modelos psicológicos. Já a questão do “inconsciente" sempre foi considerada como uma questão "monstruosa", mesmo la bête noire das abordagens psicológicas ditas "fenomenológicas". Isto se deve, em par-

\footnotetext{
Trabalho originalmente apresentado em conferência no I Simpósio de Psicologia do Inconsciente, Curitiba, entre os dias $1^{\circ}$ e 2 de novembro de 2008 .
}

te, a confusões ou interpretações que colocam em cheque o conjunto da fenomenologia, mesmo que tenhamos significativos trabalhos que versam sobre esta questão, bem como autores que discorreram sobre a mesma, como Sartre e Merleau-Ponty.

Uma das questões que imediatamente se destaca desse conjunto é a identificação que se faz - ao se ler a "consciência" na fenomenologia - como tomando um sentido de "função" psicológica; ou mesmo a sua conexão com um modelo de fenomenologia idealista (representativa de certa fenomenologia husserliana, mais especificamente, sua segunda fase ${ }^{2}$, ao invés de considerá-la a partir do

\footnotetext{
Sobre esta questão, remetemos o leitor a uma série de textos que trabalham a perspectiva histórica e prospectiva da fenomenologia husserliana (Morujão, 1990; Dartigues, 1992; Husserl, 1992; Mohanty, 1996; Smith \& Smith, 1996; Holanda, 2002).
} 
sentido de uma consciência como constituída e constitutiva de um sujeito vivente.

Enquanto na psicologia se toma a consciência como particularidade das funções psíquicas, na fenomenologia, nos deparamos com uma "ontologia da consciência". A Fenomenologia - como corrente de pensamento - responde fortemente ao contexto anticonsciencialista do início do século XX (aqui representado, basicamente, por suas principais forças, a saber, a psicanálise na Europa e o behaviorismo nos Estados Unidos).

Há, contudo, a necessidade de fazermos uma crítica - nesse particular, ou seja, aos contextos anticonsciencialistas - naquilo que iremos nos referir como tendo constituído certo "imperialismo do inconsciente", tanto no que se refere à operacionalidade do fenômeno, quanto a uma suposta imposição de direito sobre o conceito; ou à dominância de uma idéia que desapropria o sujeito da consciência, colocando-o como sujeito de uma suposta "inconsciência" constitutiva, como podemos mesmo observar na metáfora do filme Matrix.

Ao se colocar o problema "da" consciência ou "do" inconsciente, comete-se um erro epistêmico de posicionar vivência ou realidade (aqui apontados apenas como exemplos) do ponto de vista da objetivação, ou seja, torna-se um fenômeno em "coisa”. Este é o clássico erro da naturalização do fenômeno psicológico que, historicamente, a psicologia tem esbarrado. Ainda nesta direção, a suposta oposição consciência-inconsciente reflete o mesmo, o que se resume na mesma questão. Consciência - para a fenomenologia - é ato, é movimento, portanto, não se identifica com uma "coisa".

Poderíamos falar do inconsciente a partir da leitura que Sartre, p. ex., faz da psicanálise com seu existencialismo; mas devemos cuidar para que não sejam feitas aproximações apressadas entre os dois contextos, dado que a fenomenologia se afasta da psicanálise quando esta concebe o inconsciente como infraestrutura (ou como "superestrutura”), cujo dinamismo poderia ser interpretado nos termos de um pensamento causal, como um sistema de forças impessoais assimiláveis às forças

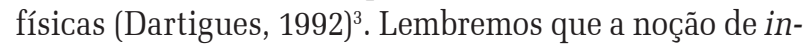
tencionalidade retira a idéia de interioridade do seio da psicologia.

O próprio Sartre faz uma distinção entre uma psicanálise empírica, que postula a existência de um psiquismo inconsciente; e uma psicanálise existencial, que rejeita tal postulado e considera o fato psíquico como sempre co-extensivo à consciência. Convém ainda lançar luzes sobre as palavras de Dartigues, a respeito dessa concepção sartreana:

Cumpre lembrar, com efeito, que um estado psíquico, uma conduta, podem ser irrefletidos sem por isso dei-

\footnotetext{
3 Igualmente não iremos nos deter sobre as aproximações, que são igualmente múltiplas; a estas correlações remetemos o leitor a outros autores (Spiegelberg, 1972; Bucher, 1983, 1989; Baas, 1998).
}

xarem de ser conscientes. Por isso, pode-se dizer que a escolha original é, com efeito, consciente sem nem por isso ter sido refletida, portanto sem ser conhecida (Dartigues, 1992, p. 109).

Poderíamos ainda seguir o caminho da "desconstrução" heideggeriana da Psicanálise, a partir do que Heidegger aponta - em carta a Medard Boss, datada de 1960 - como sendo "fatal" a distinção entre o consciente e o inconsciente (Loparic, 2001b, 2002). Como assinala Loparic (2002, p. 270):

(...) a 'divisão do psíquico [des Psychischen] em consciente e inconsciente' é considerada por ele como 'pressuposto fundamental' - como 'o primeiro shiboleth da psicanálise' - e usada para definir a metapsicologia como teoria do psiquismo inconsciente ('psicologia do inconsciente'), em oposição à teoria do eu ou do psiquismo consciente ('psicologia do eu' ou 'psicologia da consciência').

No caso da psicanálise, os fenômenos da repressão, do reprimido, do édipo e do inconsciente, são considerados pelo próprio Freud como os shiboleths - ou os identificadores visíveis da psicanálise, referindo-se a qualquer palavra que identifica seu falante como membro ou não de um grupo particular - e que Heidegger comenta.

Sua intenção não é negar esses fatos clínicos, mas tão somente redefinir seus significados em outro campo semântico, qual seja, o do ser-no-mundo. O que Heidegger contesta é a linguagem freudiana, inspirada numa metafísica da subjetividade e num projeto de objetificação da natureza (Loparic, 2001b, 2002).

Poderíamos ainda partir das proposições de Ludwig Binswanger, talvez a melhor perspectiva para tratar do assunto, mas tomaremos outro caminho. $\mathrm{O}$ caminho de um simples questionamento e de uma problematização para o contexto das ciências psicológicas. A proposta, pois, desse artigo é tão somente apontar algumas "notas" de reflexão sobre a questão do binômio consciência-inconsciente. Principiemos pelo que denominaremos preliminarmente como "análise semântica" da questão, com o intuito de uma aproximação à perspectiva da Fenomenologia.

\section{Uma Análise Semântica da Questão}

Façamos uma breve análise semântica das palavras que nos remetem aos conceitos que estamos discutindo, de modo a compreendermos a essência da questão, do ponto de vista de uma fenomenologia (convém, ainda, entender que por uma "fenomenologia" estamos fazendo entender uma ação direta geral e complexa na realidade e não um ato isolado, desta ou daquela corrente de pensamento). 
Por semântica estamos aqui compreendendo a "ciência das significações”, ou seja, aquilo que remete ao distintivo, ao que significa, ao que compõe o sentido das palavras e de seus enunciados, como posto no Dicionário Houaiss da Língua Portuguesa (Houaiss, 2002). Tomaremos este dicionário por base inicial pelo fato deste ser um dos principais veículos de acesso à nossa língua na atualidade e por ter - por detrás de suas significações - análises etimológicas que auxiliam no acesso aos diversos sentidos das palavras.

Nesta direção queremos apenas nos apropriar de algumas representações associadas aos vocábulos. Podemos principiar pelas suas apropriações tanto como substantivos ou como adjetivos.

Observemos que "inconsciente" é um adjetivo de dois gêneros, relativo aos seguintes significados (Houaiss, 2002, p. 1598):

a) "Que não é dotado de consciência”, "incônscio" (como quando dirigido à vida dos vegetais, p. ex.);

b) "Que perdeu o conhecimento, que está privado de consciência, encontra-se em estado de torpor" (quando referido a um doente, p. ex.);

c) "Feito de maneira irresponsável, inconseqüente" (igualmente relativo a "coisas" ou usado metaforicamente, como quando se diz que "uma política “x” está levando a..”);

d) "Que acontece sem que se preste atenção; automático, maquinal, involuntário” (quando referido a gestos ou reflexos, p. ex.).

É ainda um adjetivo e substantivo de dois gêneros (Houaiss, 2002, p. 1598):

e) "Que ou aquele que não se dá conta de certas coisas, não percebe as circunstâncias a sua volta" (aquele sujeito é $i$ do perigo ou é um $i$ que vive no mundo da lua);

f) "Que ou aquele que age impensadamente, sem medir o alcance de suas palavras ou de seus atos; insensato, irresponsável, inconseqüente”.

Inconsciente é ainda um adjetivo de dois gêneros e substantivo masculino, quando a rubrica refere-se às ciências médica ou psicológica (Houaiss, 2002, p. 1598):

g) "Que ou o que não pertence aos fenômenos vividos" (diz-se de processo ou conjunto de processos);

h) "Relativo a ou o estado em que o indivíduo se encontra temporária ou permanentemente privado de consciência” (como p. ex., nos casos de coma);

i) "Que ou o que, independentemente do motivo, não pode ser percebido pelo indivíduo que o vivencia" (como, p. ex., a secreção de um hormônio);

j) Na Psicologia, "que ou o que não é consciente, mas pode influenciar o comportamento sob forma simbólica ou sublimada" (referindo-se, aqui, a "processos psíquicos");

k) E na Psicanálise, "segundo a primeira teoria da psique formulada por Freud, que ou o que é constituído por conteúdos recalcados aos quais foi barrado o acesso aos sistemas pré-consciente e consciente, nos quais se desenrolam processos dinâmicos que contribuem para determinar a vida consciente" (aqui, igualmente se fala de um sistema do aparelho psíquico).

No total, temos onze acepções para o termo inconsciente no dicionário Houaiss. Desses, quatro são adjetivos puros, e os demais são adjetivos relacionados. Como adjetivo, uma palavra acrescenta qualidades ou modifica um substantivo. Já o substantivo é o que designa um ser real (concreto) ou que expressa uma substância. No caso do "inconsciente", este é substantivado quando apropriado pela psicanálise.

Observemos agora o vocábulo consciente. Em onze de suas doze acepções é igualmente um adjetivo de dois gêneros, referindo-se a (Houaiss, 2002, p. 806):

a) "Que tem conhecimento de sua própria existência" (como em animal $C$ );

b) "Que tem capacidade de pensar, desejar, ter um propósito, perceber";

c) "Que envolve raciocínio, conhecimento, percepção, decisão";

d) "Que tem conhecimento de (algo); cônscio, ciente, informado";

e) "Tratado ou executado com conhecimento crítico, cuidado, honestidade; responsável, sério";

f) "Que se encontra na posse plena de suas faculdades mentais; que não se encontra embotado pelo sono, por desmaio ou estupor; acordado, desperto";

g) "Que assume uma postura ideológica; que tem consciência de sua condição ou papel”;

h) "Que se preocupa com o próximo e não age levado por motivos egoístas; responsável”;

i) "Que procede com consciência; probo";

j) "Feito com meticulosidade, cuidado";

k) Na Medicina, "que consegue responder adequadamente a estímulos sensoriais".

O vocábulo consciente, apenas ganha uma acepção relacionada a substantivo (ainda que associado ao adjetivo de dois gêneros) ou como substantivo masculino, quando relativo à ciência psicológica ou à psicanálise, como temos em (Houaiss, 2002, p. 806):

l) "Relativo a ou aspecto da psiquê que constitui o lado da vida mental a que se tem acesso instantâneo e que está em maior contato com a realidade exterior"; 
m) "Nível superior da vida mental do qual uma pessoa tem consciência, ao contrário dos processos do inconsciente";

n) "Um dos três sistemas da primeira teoria tópica de Freud acerca da psiquê, que postula a existência do inconsciente, do pré-consciente e do consciente".

Agora, tomemos o vocábulo consciência. Todas as suas dezesseis acepções remetem a substantivações, como substantivos femininos (Houaiss, 2002, p. 806):

1) "Sentimento ou conhecimento que permite ao ser humano vivenciar, experimentar ou compreender aspectos ou a totalidade de seu mundo interior";

2) "Sentido ou percepção que o ser humano possui do que é moralmente certo ou errado em atos e motivos individuais, funcionando como o juiz que ordena acerca de coisas futuras e que se traduz em sentimentos de alegria, satisfação, ou de culpa, remorso, acerca de coisas passadas";

3) "Sistema de valores morais que funciona, mais ou menos integradamente, na aprovação ou desaprovação das condutas, atos e intenções próprias ou de outrem";

4) "Conjunto de idéias, atitudes, crenças de um grupo de indivíduos, relativamente ao que têm em comum ou ao mundo que os cerca";

5) "Conhecimento, convicção, discernimento, compreensão”;

6) "Entendimento acerca de ou interesse por determinado tema ou idéia, esp. por problemas sociais e políticos";

7) "O ser humano, tomado como ser pensante ou espiritual; alma, espírito, mente";

8) Como derivação, por metonímia, "indivíduo cuja consciência (política, moral, religiosa etc.) é especialmente firme, obstinada e/ou representativa de determinada corrente ou fase";

9) "Peça na extremidade da haste da broca manual, constituída por uma chapa curva de metal que o operador encosta ao peito quando quer exercer pressão sobre a ferramenta";

10) Na Ética, é a "faculdade, princípio ou propriedade (inata ou, para a teologia antiga, de implantação divina) acima da qualidade moral dos atos e motivos de uma pessoa, a qual funciona como juízo do certo, associado ao Bem, e do errado, associado ao Mal";

11) Na Filosofia, "faculdade por meio da qual o ser humano se apercebe daquilo que se passa dentro dele ou em seu exterior";

12) Na Medicina, "estado do sistema nervoso central que permite a identificação precisa, o pensamento claro e o comportamento organizado" (em oposição e inconsciência);
13) Na Psicologia, "nível da vida mental do qual o indivíduo tem percepção (ao contrário dos processos inconscientes)";

14) Ainda na Psicologia, "fase subjetiva de uma parte dos processos físicos (esp. dos processos perceptivos) que se produzem no sistema nervoso";

15) Na Psicanálise como "consciência psicológica";

16) E na indústria têxtil, "nos teares manuais, pedra suspensa por um cordel, us. para retesar a trama”.

Em todas essas acepções, temos o fato que - tal qual estamos associando ao ponto de vista fenomenológico - o que há efetivamente, relacionado ao humano ou ao sentido do humano, portanto, como substantivação, é a consciência aqui considerada como ato. Tudo o mais se refere- $a$, como adjetivação, portanto, se remete- $a$ consciência, enquanto o ato primordial. Metaforicamente, o substantivo aponta, pois, para o ato em si.

\section{Theodor Lipps e a Descoberta do Inconsciente}

Theodor Lipps (1851-1914) foi um importante filósofo alemão, que influenciou boa parte dos professores de sua época. Entre seus admiradores encontram-se personalidades como o próprio Freud. Inclusive se atribui a noção de "subconsciente" ou de "pré-consciente" a Lipps.

Lipps trabalha igualmente com o conceito de "empatia”, trazido da filosofia da arte - a partir de Robert Vischer - que falava de uma "simpatia estética" ou Einfühlung; posteriormente Lipps toma essa noção de Husserl, com quem compartilha muitos de seus estudantes (Lipps, 2001; Loparic, 2001a). No contexto da fenomenologia, a figura de Lipps aparece ainda ligada a Brentano e à construção do movimento fenomenológico.

Segundo Loparic (2001a), o nome de Lipps - apesar de desconhecido da maioria dos leitores da psicanálise - é citado por Freud "em momentos decisivos" da constituição de sua metapsicologia e de sua teoria do inconsciente. Freud se depara com as idéias de Lipps quando, a partir de 1898 - já trabalhando na sua teoria dos sonhos - abandona sua teoria "fisiológica” do psiquismo, em prol de uma explicação "psicológica” dos fenômenos clínicos, retornando a ele no final de sua vida, quando reflete sobre a estrutura da sua teoria. Há menções honrosas de Freud a Lipps, como em carta a Fliess, datada de 28 de agosto de 1898, onde Freud se refere a ele como uma das mentes mais lúcidas dentre os escritores da filosofia de sua época (Loparic, 2001a).

Lipps apresenta seu conceito de inconsciente no Terceiro Congresso Internacional de Psicologia, em Munich, em 1897, em conferência que viria a ser publicada nos textos finais do referido encontro (Lipps, 2001). Escreve-nos Lipps: 
Essa conferência trata menos de uma pergunta psicológica do que da própria psicologia. Não se pode analisar o conceito de inconsciente na psicologia sem, pelo menos, tocar na pergunta psicológica mais geral da natureza e tarefa dessa ciência (...) Se a psicologia se colocasse como única tarefa descrever vivências conscientes, ela não precisaria, de modo algum, do conceito de inconsciente. Mas uma tal psicologia seria um disparate (...) não poderia ser outra coisa do que a narrativa ou o relato de meus próprios processos conscientes individuais. Não haveria, para uma tal psicologia, nenhum 'por que' ou 'para que' (Lipps, 2001, p. 335).

Não haveria, segundo Lipps, nenhuma relação de significado entre essas descrições. A psicologia descritiva deveria discutir uma série de "estados de coisas", tais como um "juízo proposicional” (Satzurteil), "juízo de sentido" (Sinnurteil) ou ainda como representações de coisas (Sachvorstellungen) ou de significados (Bedeutungsvorstellungen).

Seu questionamento vai numa direção que, para uma psicologia descritiva, existiriam apenas as vivências conscientes. Um juízo de entendimento ou uma tomada de posição, uma valoração estética, podem ser tanto conscientes quanto inconscientes. Felizmente nunca existiu tal psicologia descritiva. E acrescenta que, "tornar compreensíveis os conteúdos da consciência e sua existência, esta é exatamente a tarefa da psicologia” (Lipps, 2001, p. 338).

Compreensão, para Lipps, envolve a ordenação dos fatos da experiência imediata e seu encadeamento causal ou sua conformidade a leis, o que deve - a seu ver ser o fim da psicologia. Quais os fatos que a psicologia se debruça por compreender? Os "fatos da consciência", que podem ser identificados com as sensações, as representações, os pensamentos, etc.

É um fato notável - um fato também psicológico, mas de difícil compreensão - que alguns psicólogos parecem dar tão pouca importância à resposta a tais perguntas e, portanto, à determinação inequívoca dos objetos de sua ciência. E, no entanto, é disso que depende, assim como tantas outras, também a muito discutível pergunta pelo inconsciente (Lipps, 2001, p. 338).

Segundo Lipps, a resposta passa a ser "o consciente”, identificado com o objeto da psicologia, e associado a "psíquico". O "inconsciente" e o físico, estariam fora da psicologia.

Psicologia e física tratam, em parte, exatamente $d a$ mesma coisa. Nem tudo o que é psicológico é físico ou fisicalista. Mas todos os objetos da física são, enquanto percepções, representações e pensamentos numa mente humana, objetos da psicologia. O que faz a diferença é o modo de consideração (Lipps, 2001, p. 339).
Diferenças no modo de consideração: objetos da experiência imediata seriam considerados pela física como sinais, enquanto que para a psicologia seriam seu objeto próprio. Mas complementa com outros modos de relativizar: "Estaremos mais perto da verdade se dissermos, empregando uma expressão já usada anteriormente, que a psicologia tem como objeto de sua consideração as vivências conscientes" (Lipps, 2001, p. 340).

Ora, as vivências se referenciam a alguém que as vivencia, ou seja, aos sujeitos dessa vivência. Temos assim, um "para quem" os fatos estão presentes. Este é o legado da noção de intencionalidade na fenomenologia: o resgate do sujeito por detrás da experiência.

Quando tomamos a psicologia brentaniana como ponto de partida, nos vem questões como: Porque os objetos da psicologia podem ser as sensações, as representações, as idéias? Porque remete à interrelação entre esses "atos", como diria Brentano, e os "sujeitos" desses atos. Assim, podemos dizer que as representações, p. ex., são os objetos por excelência da psicologia, em lugar do "representado". Não se toma - como objeto da psicologia - o objeto em si, puro e simples, mas o "objeto-em-relação-a" um sujeito para o qual este é um fato.

Retomemos Lipps:

O mesmo também está implícito no esclarecimento de que os objetos da psicologia são as sensações, as representações, os pensamentos, etc., em oposição ao que é sentido, representado, pensado; dito de outra maneira, o psíquico são os 'atos' de sentir, de representar e de pensar. (...) Mas, na verdade, esses atos não existem em nossa experiência imediata. Se é que existe, então, o ato ou o processo de representação - o modo como é feito com que algo representado esteja aí para mim - pertence ao reino do inconsciente (Lipps, 2001, p. 340).

Tenho uma consciência imediata de que algo está lá "para mim", ou seja, minha consciência me remete-a-algo com o qual se estabelece uma nítida e inextrincável relação formal - aqui no sentido do que "toma forma”, isto é, não há a forma apenas na consciência ou apenas no mundo, mas em sua interação:

O perceber, o representar e o pensar são a existência do percebido, do representado e do pensado para mim, ou seja, as percepções, as representações e os pensamentos são o percebido, o representado e o pensado, na medida em que são algo que pertence a mim ou ao sujeito, algo subjetivamente efetivo. O mesmo percebido, representado e pensado é algo físico, ou seja, é uma efetividade objetiva, contanto que, e na medida em que, não dependa de um sujeito. Essa oposta relação ao sujeito ou ao eu, e só ela, separa o psíquico do físico (Lipps, 2001, p. 340). 
É, pois, pelo "ato" da consciência, ou melhor, pela consideração da consciência enquanto ato que o mundo se dá para mim, para um sujeito e, igualmente, o próprio sujeito se dá a si próprio, visto que a fenomenologia aponta para esta ontologia implícita dos atos da consciência, ao qual Lipps assente, quando diz: "Quando sinto um querer, sinto a mim mesmo" (Lipps, 2001, p. 342).

Façamos agora outra breve analogia com a psiquiatria de herança fenomenológica, tomando algumas idéias de Blankenburg por exemplo.

\section{Relação Sujeito-Mundo na Psicopatologia}

Wolfgang Blankenburg foi um continuador do trabalho de Binswanger. Representante da tradição contemporânea francesa da escola fenomenológica de psiquiatria (que nos remete ao legado de Minkowski, de Henri Ey e outros), deixou ressonância de seu pensamento em outros representantes da psiquiatria fenomenológica, como Arthur Tatossian e Jean Naudin.

Blankenburg aponta para a relação sujeito-mundo na psicopatologia, dizendo que "a relação consigo e com o mundo é, na experiência dos esquizofrênicos, mais fundamentalmente perturbada do que nos pacientes neuróticos. Consequentemente, a terapia deve se definir de maneira mais basal" (Blankenburg, 1989, p. 181). Para o autor, na psicose, é o problema da realidade que é em causa. Mas qual realidade? A realidade que se "constitui" para o sujeito.

No que consiste essa "constituição"? No sentido que Husserl aponta que é a atividade do sujeito pela qual um objeto ou uma vivência me é dada e adquire para mim um sentido. "No contexto fenomenológico, constituição significa a estrutura interna da construção segundo a qual qualquer coisa é, para nós e para nossos pacientes, aí. É o que resulta que apreendemos alguma coisa 'como algo' ou - nos termos heideggerianos do Sein und Zeit - "enquanto qualquer coisa", assinala Blankenburg (1989, p. 181).

Com a intencionalidade, as diferenças entre consciente, inconsciente e pré-consciente se tornam, pois, secundárias. Sobre isto aponta Blankenburg (1989): "No lugar da consciência, devemos colocar o conceito mais geral de atos doadores de significações, que podem ser de diferentes espécies, comportando também reações não conscientes, quer sejam da ordem do sentimento ou mesmo da ordem da corporeidade" (p.181).

Isto aparece descrito, na obra husserliana, nas noções de síntese ativa e síntese passiva, que respondem a questões tais: Como uma coisa se constitui como coisa para uma pessoa? Ou, como alguém se constitui como alguém, enquanto alguém para um outro? Como assinala Depraz (2007), Husserl - ao escrever Sobre a Síntese Passiva - aponta para um sentir que "de fato surge de uma pré-consciência da consciência, e que não pode ser objeto de uma localização objetivante a não ser em uma reflexão posterior: sua gênese é imanente, totalmente situada em minha carne, pré-reflexiva, passiva e, portanto, inobjetivável" (p. 62-63).

Em outras palavras: a intencionalidade, ao posicionar o sujeito diante do mundo de objetos, apresenta a consciência como abertura para este mundo, mundo este que se torna $a$ posteriori um mundo interhumano, que apresenta o conjunto de sujeitos ao próprio sujeito. Blankenburg ainda assinala uma crítica aos modelos psicanalíticos ao apontar:

Finalmente, não podemos nos desfazer da impressão que muitos dos modelos psicanalíticos não tem apenas a função de deixar manejável e elaborável o material que se apresenta mas que eles servem também para dar ao analista alguma coisa com a qual ele possa se apoiar para evitar precisamente o risco de se colocar na abertura do encontro interhumano (Blankenburg, 1989, p. 185).

Esta crítica pode levar a conclusões que apontariam simplesmente para oposições entre a fenomenologia e a psicanálise. É mesmo comum certo tipo de oposição entre fenomenologia e psicanálise, que as coloca como duas formas "opostas" em termos de prática clínica, uma sendo "recobridora" e a outra "descobridora", sendo aqui entendida a "recobridora" como aquela que não questiona para além das aparências. Mas o próprio Blankenburg (1989) aponta para a falsidade dessa afirmação.

A questão que se põe é se a perspectiva fenomenológica se restringe ao que se pode designar como sendo o préconsciente, não ascendendo ao inconsciente dinamicamente ativo. Ora, a perspectiva da intencionalidade fenomenológica remete justamente ao princípio da descoberta e, portanto, sendo contrária a uma idéia "recobridora" ou limitada no desvelamento. $\mathrm{O}$ sentido fundamental deve ser o desvelamento ou des-ocultamento e não de revelação de algo incompatível com um sentido imediato.

Como aponta Blankenburg (1989), as direções da fenomenologia e da psicanálise não coincidem: "Trata-se, antes, de uma fenomenologia da colocação a descoberto do logos dos fenômenos e não de uma dinâmica pulsional" (p.188). Mas há identificações entre as duas perspectivas no tocante à questão do inconsciente, como temos em Merleau-Ponty.

\section{Um Exemplo: A Crítica de Merleau-Ponty à Noção de Interioridade na Psicologia}

Há, na Fenomenologia posterior a Husserl, críticas as mais diversas - positivas ou não - aos modos de apropriação do conceito de inconsciente, em particular ao modelo proposto pela psicanálise. Temos em Sartre, p. ex., críticas ácidas à formulação freudiana de inconsciente. Já 
em Merleau-Ponty temos uma "noção positiva de inconsciente”, nos textos produzidos entre 1953 e 1961 (Coelho Jr., 1991, p. 125).

Merleau-Ponty apresenta uma forma particular de se localizar no campo da fenomenologia, em parte por conta de sua posição diferenciada diante da obra de Husserl (dado que se posiciona diante dos "inéditos" e do "último Husserl" - ou o Husserl do Lebenswelt, o "mundo da vida”); em parte por conta da independência e autonomia de seu caminho filosófico, além de um interesse vivo pela psicanálise (Coelho Jr., 1991).

Esta diferenciação coloca Merleau-Ponty na direção de uma fenomenologia do corpo - a partir de uma fenomenologia da percepção -, sendo o corpo o lugar privilegiado da existência. Com isto, em tese, opõe uma fenomenologia das essências a uma fenomenologia da existência. Coelho Jr. (1991) aponta para a relação de Merleau-Ponty com a psicanálise exatamente por ter como eixo de sua filosofia, a questão da percepção e não da consciência.

A psicanálise será uma interlocução privilegiada para Merleau-Ponty, estando presente tanto em suas primeiras obras - como A Estrutura do Comportamento, de 1942, e Fenomenologia da Percepção, de 1945 - quanto em obras tardias, especialmente a partir de 1953, quando "a psicanálise passará a ser (...), referência obrigatória” (Coelho Jr., 1991). Em relação a esse diálogo mais estreito entre Merleau-Ponty e a psicanálise, destacam-se alguns textos, como o curso sobre "Natureza e Logos: o corpo humano”, de 1959; o prefácio que Merleau-Ponty escreve ao livro de Angel Hesnard sobre a obra de Freud, de 1960; bem como seu famoso O Visível e o Invisível, de 1964 (Coelho Jr., 1991).

Ademais, a proximidade existente entre MerleauPonty e personalidades como Lacan e Pontalis, atestam esses liames, como exemplo de deferência em sentido inverso, como temos nos artigos escritos por ambos em 1961, na revista Les Temps Modernes, em número especial dedicado ao fenomenólogo francês. Para MerleauPonty:

A consciência não é concebida como um em si, como algo independente do mundo e dos objetos. É sempre consciência de, consciência aberta ao mundo, sempre consciência de algo. Merleau-Ponty aprofunda essa concepção nomeando a consciência aberta ao mundo, a consciência intencional de Husserl de consciência perceptiva. (...) A consciência deve ser compreendida sempre como consciência perceptiva, como consciência que mantém, enquanto ligada inextrincavelmente ao corpo, um permanente diálogo com o mundo (...) (Coelho Jr., 1991, p. 130).

Nesta direção, o filósofo francês situa a consciência no corpo e o corpo no mundo, numa constante tentativa de alargar a descrição da consciência husserliana, posicionando-a na experiência sensível. Sendo assim, pensar o sujeito - para Merleau-Ponty - é pensá-lo enquanto corpo no mundo, deslocando o ato de conhecer da "consciência” para o "corpo-vivido". "Não se fala mais em uma consciência que conhece, mas em um 'corpo-conhecedor", (Coelho Jr., 1991).

Já em seu primeiro livro, Merleau-Ponty critica o conceito de inconsciente em Freud por considerá-lo uma formulação que mantinha o modelo mecanicista na psicologia, ou seja, tornando o inconsciente outra representação causalista para os estados mentais. Um modelo de inconsciente que é concebido a partir da consciência (aqui entendida de modo original) não interessa a Merleau-Ponty. Como aponta Coelho Jr. (1991), neste momento de sua obra, Merleau-Ponty percebe que não há o que buscar no conceito de inconsciente, dado que é o corpo o centro de referências da existência e o espaço onde a existência é vivida, e onde convergem o "prépessoal" e o "pessoal".

Posteriormente, ainda questiona o conceito de inconsciente em seu curso de 1954 (Merleau-Ponty, 1968), quando aponta para um "segundo sujeito pensante", introduzido por Freud, com o nome de inconsciente.

Como nossa intenção não é tratar extensivamente da crítica merleau-pontyana ao inconsciente freudiano, mas tão somente apontar alguns elementos para nossa reflexão, remetemos o leitor a trabalhos mais elaborados com respeito a esta temática (como Coelho Jr., 1991, p. ex.).

A questão aqui é apenas resgatar a crítica ao modelo de "interioridade" contido nessas apropriações da idéia de inconsciente, com vem sendo trabalhadas ao longo da história da psicologia e da psiquiatria. No Visível e $o$ Invisível, Merleau-Ponty (2003) fala do visível como possuindo a "estrutura" do invisível. Assim, situa a experiência sensível entre o visível e o invisível (Coelho Jr., 1991). E é este sentido de continuidade que nos interessa aqui, para afirmar a Fenomenologia como um modelo de consciência do mundo.

\section{Fenomenologia da Consciência como Fenomeno- logia do Mundo}

Houve, em certo tempo da história da psicologia moderna, uma divisão - um tanto quanto curiosa - entre "psicologias profundas" e as demais. Com isto, apontavam seus defensores, haveria um "lugar", mais "profundo", para além da consciência, que seria o lugar "verdadeiro" ou "real" do humano. A rigor, esta cisão apontava para um conjunto de "psicologias da consciência" (mais superficiais) e um conjunto de "psicologias do inconsciente" (daí a justificativa para a expressão referente a "profundezas" ou "profundidade").

Isto representou uma lamentável cisão no contexto, principalmente, das práticas clínicas ou das antigas "teorias da personalidade" - como podemos observar nos tradicionais manuais de história ou de teorias da perso- 
nalidade, como p. ex., Wolman (1977) ou Mueller (1978) - onde se criou uma situação de negação de aspectos da realidade, de parte a parte. Um bom exemplo seria uma espécie de "negligência" da parte dessas psicologias da consciência com a questão do inconsciente, levando mesmo muitas a negar sua existência. Um bom exemplo pode ser a caracterização da questão do inconsciente como um "fetiche" ou "adoração pelo desconhecido", como encontramos em Perls, Hefferline \& Goodman (1997), quando os autores se referem a uma "gestalt oculta".

O que nos interessa é o fato epistêmico que coloca a psicologia diante da realidade fenomenológica do mundo. Ao contrário de proceder a uma simples exclusão do campo da discussão de tal conceito, parece-nos mais importante fazer uma referência crítica ao mesmo, como temos na crítica de Merleau-Ponty do "homem interior", dado que homem está no mundo. Igualmente a consciência não pode ser identificada com a interioridade como o fez a psicologia - mas com um ato que inviabiliza o fechamento do sujeito de si próprio; pois, consciência é abertura.

Esta é a primazia da "virada" radical da intencionalidade, para Husserl. A retirada do fechamento do sujeito sobre si, o "ultrapassamento" do solipsismo cartesiano operado pela intencionalidade que torna a consciência a clareira da existência. Se tomarmos a posição de Merleau-Ponty, por exemplo, de que o corpo é o "lugar" de convergência e desdobramento do estar-no-mundo encarnado, então a questão da consciência é a questão da relação direta entre o sujeito e o mundo e, portanto, a questão da vivência.

Dado que a fenomenologia diz de uma indivisibilidade nesta relação entre sujeito e mundo, então temos que admitir que a consciência não se resume a um "penso que...", mas a um "eu posso", ou seja, a um movimento. Neste sentido, não se trata igualmente de se desfazer da questão do inconsciente, mas de recolocá-lo em diálogo e em relação direta com o sujeito consciente. A experiência humana, na fenomenologia, é compreendida como um continuum (como temos explicitado, por exemplo, na experiência do tempo vivido).

Neste sentido, não se "explicita" claramente o "inconsciente", exatamente por este não ser uma "coisa”. Da mesma forma, não mais se fala de algo "oculto", pois mesmo o lado do cubo que não percebo "está lá”, e eu "sei” disto. O que se explicita, pois, é que todo fenômeno comporta uma presença e uma ausência. Este é o legado da noção de intencionalidade, a sua dimensão dinâmica, que pode ser igualmente explicitada pelos seus dois “tipos”: a intencionalidade temática, que nos remete ao saber do objeto e ao saber deste saber sobre o objeto; e a intencionalidade operante, ou "em exercício", que é a visada do objeto em ato (ainda não refletido). A primeira persegue a segunda, que sempre a precede, mas nunca é alcançada.

Por fim, a reflexão (ou o saber consciente) só se exerce sobre um fundo de irreflexão. E esta é a composição de todo o campo. Como temos em Merleau-Ponty (1968), o inconsciente não deve ser procurado no "fundo" de nós mesmos, mas diante de nós, em articulação com o mundo; portanto, quem percebe e o que é percebido partilham de um mesmo campo. Daí, o inconsciente deixa de ser parte de uma estrutura intrapsíquica - é retirado do plano do "psíquico", do "mental" - para ser situado - como a consciência encarnada - no mundo. Há o visível e o invisível; não há visibilidade pura, tampouco pura invisibilidade, mas entrelaçamento. É neste ponto que o poeta MerleauPonty encontra o filósofo Fernando Pessoa, quando este afirma que "o único sentido oculto das coisas é elas não terem sentido oculto algum”.

\section{Referências}

Baas, B. (1998). De la Chose à l'Objet. Jacques Lacan et la Traversée de la Phénoménologie. Leuven: Peeters Vrin.

Blankenburg, W. (1989). La signification de la phénoménologie pour la psychothérapie, Em P. Fédida \& J. Schotte (Eds.), Psychiatrie et Existence (p. 181-1980). Paris: Jerôme Millon.

Bucher, R. E. (1983). Fenomenologia e Psicanálise. Revista Brasiliense de Psiquiatria, 3/1, 33-43.

Bucher, R. E. (1989). Psicoterapia pela Fala. São Paulo: E.P.U.

Coelho Jr, N. (1991). O Inconsciente em Merleau-Ponty. Em F. Knobloch (Org.), O Inconsciente. Várias Leituras (p. 123146). São Paulo: Escuta.

Dartigues, A. (1992). O Que é Fenomenologia. São Paulo: Moraes.

Depraz, N. (2007). Compreender Husserl. Petrópolis: Vozes.

Holanda, A. F. (2002). O Resgate da Fenomenologia de Husserl e a Pesquisa em Psicologia. Tese de Doutorado em Psicologia, Campinas, Pontifícia Universidade Católica de Campinas.

Houaiss, A. (2002). Dicionário Houaiss da Língua Portuguesa. São Paulo: Objetiva.

Husserl, E. (1992). Conferências de Paris. Lisboa: Edições 70.

Lipps, T. (2001). O Conceito de Inconsciente em Psicologia. Natureza Humana, 3, 2, p. 335-358.

Loparic, Z. (2001a). Theodor Lipps: uma fonte esquecida do paradigma freudiano. Natureza Humana, São Paulo, 3, 2, p. 315-334.

Loparic, Z. (2001b). Além do Inconsciente: Sobre a desconstrução heideggeriana da psicanálise. Natureza Humana [online], vol.3, $\mathrm{n}^{\circ} .1$ [citado 02 Novembro 2008], p. 91140. Disponível na World Wide Web: http://pepsic.bvspsi.org.br/scielo.php?script=sci_arttext\&pid=S151724302001000100004\&lng $=$ pt\&nr $m=i s o$ 
Loparic, Z. (2002). Além do Inconsciente: Sobre a desconstrução heideggeriana da psicanálise. Em R. T. de Souza \& N. F. de Oliveira (Orgs.), Fenomenologia Hoje II. Significado e Linguagem (p. 269-315). Porto Alegre: Edipucrs.

Merleau-Ponty, M. (1945). Phénoménologie de la Perception. Paris: Gallimard.

Merleau-Ponty, M. (1968). Le Problème de la Passivité: Le sommeil, l'inconscient, la mémoire. Résumés de Cours. Collège de France 1952-1960.

Merleau-Ponty, M. (2003). O Visível e o Invisível. São Paulo: Perspectiva.

Mohanty, J. N. (1996). The Development of Husserl's Thought. Em B. Smith \& D. W. Smith, The Cambridge Companion to Husserl (p. 45-77). Cambridge: Cambridge University Press.

Morujão, A. F. (1990). O Movimento Fenomenológico. Em Logos. Enciclopédia Luso-Brasileira de Filosofia, Lisboa: Verbo.

Mueller, F-L. (1978). História da Psicologia. São Paulo: EPU.

Perls, F., Hefferline, R., \& Goodman, P. (1997). Gestalt-Terapia. São Paulo: Summus.

Smith, B., \& Smith, D. W. (1996) (Eds). The Cambridge Companion of Husserl. Cambridge: Cambridge University Press.

Spiegelberg, H. (1972). Phenomenology in Psychology and Psychiatry. Evanston: Northwestern University Press.

Wolman, B. B. (1977). Teorías y Sistemas Contemporáneos en Psicología. Barcelona: Ediciones Martinez Roca.

Adriano Holanda - Doutor em Psicologia e Professor Adjunto da Universidade Federal do Paraná. Endereço para correspondência: Departamento de Psicologia, Universidade Federal do Paraná, Praça Santos Andrade, $\mathrm{n}^{\circ}$ 50, sala 215 (Ala Alfredo Buffren). CEP 80.060.240 - Curitiba, PR. Email: aholanda@yahoo.com

Recebido em 12.10 .09 Primeira Decisão Editorial em 15.02.10 Aceito em 20.05.10 